\title{
Discussion on Teaching Model of Computer Aided Design and Manufacturing Based on Constructivism
}

\author{
Peng Zhang, Xutao Liu \\ School of Mechanical Electronic and Information Engineering, China University of Mining and \\ Technology, Beijing, Beijing 100083
}

Email: zhangpeng@cumtb.edu.cn

Keywords: Computer Aided Design and Manufacturing; Constructivism; Teaching Model

\begin{abstract}
Constructivism is a new cognitive theory which emphasizes on the student-centered teaching methodology, pay attention to the students' active exploration, discovery on knowledge and active construction on the knowledge meaning. Constructivism learning theory is very adapt to the special teaching needs of computer aided design and manufacture. Combined with the actual features of computer aided design and manufacturing, this paper inquires into the constructivism teaching mode in the teaching of Computer aided design and manufacturing.
\end{abstract}

\section{Introduction}

The application of computer aided design and manufacturing (CAD/CAM) technology accelerated the development of mechanical manufacturing. CAD/CAM greatly shortened the product design and production cycle and achieve the requirement of the mechanical and electrical products for the large scale, high speed, high precision. It became the core technology for the modernization and development of manufacturing. CAD/CAM technology has been the preferred aided design tool of the related field engineering and technical personnel for the product design and analysis. It was widely used in the actual engineering design, such as machinery, electronics, construction, aviation, spaceflight, automobile, chemical industry, etc. The course has more basic concept which has the strong practicality and applicability. Its content updates quickly which has the creative and age development. Previous teaching practice has proved that the bondage of the traditional teaching mode directly affect students' learning interest and efficiency. It is difficult to meet the requirement of information society and information technology development. In order to improve the teaching effect, this paper will combine the constructivism thoughts and computer aided design and manufacturing teaching, discuss how to engaged in the teaching of computer aided design and manufacturing on the basis of constructivism learning theory, and achieve better teaching effect.

\section{Constructivism learning theory viewpoint}

Constructivism teaching ideas are penetrating into the each discipline and domain of modern education. Constructivism thinks that the traditional teaching view underestimates the complexity of teaching and learning. Constructivism teaching view pays the more attention to the students to analyze problems, solve problems, and the cultivation of creative thinking ability in the process of teaching and learning. Its core is based on the students as the center, which emphasizes the students' active exploration, discovery on knowledge and active construction on the knowledge meaning. Constructivism teaching view thinks the teachers as the organizer, instructor, helper and promoter for the students to realize construction. The learning environment elements such as situation, cooperation, conversation etc were used in the process of teaching which gave full play to the students' initiative, positivity and innovation spirit to make students effectively achieve the goal of meaning construction[1]. It can be seen that the status and function of the teachers and students have the great changes under the guide of constructivism compared with the traditional teaching. This means that the traditional teaching mode which is the teacher-centered, simple emphasis on knowledge, the students 
as an object of knowledge infusion should abandon. The teachers should adopt new teaching design ideas, new teaching mode and new methods of teaching in the process of teaching.

Constructivism learning theory is very adapt to the special needs of computer aided design and manufacture course teaching. The students utilize the autonomous learning, cooperative communication to realize the meaning construction of learning content, and gain the ability of learning and application. At the same time, computer and network technology especially suitable for the realization of constructivism learning environment which is an effective cognitive tool in the teaching process. It is an ideal cognitive tool to the constructivism learning environment. This paper will combine the constructivism teaching thoughts and CAD/CAM teaching practice, discuss the teaching mode of the computer aided design and manufacture under the guidance of constructivism.

\section{Teaching Model of Computer Aided Design and Manufacturing Based on Constructivism}

Constructivist teaching mode refers to take the student as the center, and the teacher as the role of organizer, instructor, helper and promoter in the whole teaching process. The use of the learning environment elements such as situation, cooperation, conversation gives full play to the students' initiative, positivity and pioneering spirit. It makes students to effectively realize the purpose of constructing the meaning of the current knowledge [2]. Compared with the traditional teaching, the four elements such as teachers, students and teaching materials and media in this teaching mode have their own different role. And there is a completely different relationship between each other. The role and relationship is very clear. Thus it becomes another kind of stable structure form the of the teaching activity process, namely the teaching mode based on the constructivism learning environment. Under the teaching mode of constructivism, the developed teaching methods of the computer aided design and manufacture are as following.

\section{Scaffolding Instruction}

Scaffolding instruction is to provide a conceptual framework for the students to construct knowledge. This kind of teaching mode is based on the theory of proximal development zone proposed by the famous former Soviet union psychologist Lev Vygotsky. Scaffolding should be established according to students' proximal development zone. And the new proximal development zone was continuously created through the scaffolding role. Scaffolding instruction mainly includes the following several steps.

(1) Establishment the scaffolding

Around the current study theme, conceptual framework was established according to the requirements of "the most neighboring developmental zone". The situation related to the basic content of the current study subject is presented to the students.

(2) Enter the situation

It introduced students to a certain situation of the problem.

(3) Independent exploration

It made students explore independently. It is inspired by teachers at the beginning, and then let the students themselves to analysis. The teacher should prompt timely in the process of exploring, and help students gradually rising along the conceptual framework.

(4) Group cooperative learning

Group discussion was carried out and finished the meaning of knowledge construction.

(5) Study effect evaluation

It includes the self evaluation and group evaluation.

\section{Random Access Instruction}

Because of the complexity of the things and the versatility of the question, it often can be concluded the different understanding from the different point of view. In the teaching process, teachers should 
pay attention to that the same teaching content for the different teaching objectives would be presented in a different way from the different time, different situations. Students can freely enter the learning of the same teaching content through different channels, different ways, accordingly gain the many aspects understanding of the same thing or the same problem. This is the "random access instruction". Such many entry is not like the traditional teaching mode which is simple repetition in order to consolidate the general knowledge, skills. Each entry has different learning goals and question focus. Random access instruction mainly includes the following several steps.

(6) Basic situation presentation

The situation related to the basic content of the current study subject is presented to the students.

(7) Random into learning

It is paid attention to the development of students' autonomous learning ability.

(8) Thinking development training

Teacher should pay special attention to the development of students' divergent thinking ability.

(9) Group cooperative learning

Group discussion is carried out around obtained understanding from the different side situation presentation.

(10) Study effect evaluation

It includes the self evaluation and group evaluation.

\section{Anchored Instruction}

The teaching requirements are based on infectious real problems or actual events. Because that the anchored instruction should be on the basis of real instances or problem (as "anchor"), sometimes it is referred to as "case teaching" or "based on the problems of teaching" or "situational teaching". In order to make the students understand the nature of things, law, and the links between things and other things reflected by the knowledge, teachers should let the students experience to the real environment of the real world rather than merely listen to the teacher about the introduction and interpretation of the experience. Anchored instruction mainly includes the following several steps.

(1)Establishment the situation

It can make learning happen in the situations almost the same as reality.

(2)Determination the problem

In this situation, the real events or problems closely related to the current study theme are chosen as the center of the learning content. The selected event or problem is the "anchor", the role of the link is the "anchor".

(3)Autonomous learning

Teachers provide students with the clues to solve the problem, rather than that teachers directly told the students how to solve the problem. It is paid attention to the development of students' autonomous learning ability.

(4)Cooperative learning.

It can add, amend and deepen students understanding of the current problems through different points of view.

(5)Effect evaluation.

Because that the learning process of the anchored instruction is the process to solve the problem, it can directly reflect the student's learning effect from the process. The evaluation of the teaching effect can be obtained by observing and recording the student performance in the process of learning.

Cases selection is the key to the success or failure of the anchored instruction, otherwise it will become a mere formality. Combining with the characteristics of mechanical professional students, mechanical engineering design example was chosen as case teaching. Decomposition and handle of the case must pay attention to the gradual characteristic. And the content of span cannot be too big at the beginning, it should be gradually deepen extension and meet the requirements of coverage and 
depth of knowledge points [3]. In a word, the careful design instances help the students from typical imitate to the autonomous learning, and facilitate teachers to organize the teaching content.

\section{Summary}

Teaching mode is a complete teaching system or architecture based on certain teaching ideas. According to our teaching experience, the constructivism theory follows the learner's cognitive law. And it is more advantageous to the construction of students' knowledge system and improvement of the sustainable development ability. The basic principles of constructivism learning theory has obvious consistency with the teaching requirements of computer aided design and manufacture. It has a good effect to cultivate students' innovation ability, cooperation ability, application ability.

\section{Acknowledgement}

This work was financially supported by the university curriculum construction and teaching reform project "computer aided design and manufacture" course construction and reform (K130411).

\section{References}

[1] Yu shengquan, Yang xiaojuan, He kekang. Teaching design mode based on the constructivism. e-Education research,2000,(12):7-13.

[2] He kekang. Constructivism teaching mode, teaching method and teaching design. Journal of Beijing Normal University(Social Science Edition), 1997(5):74-81.

[3] Wei Baoping. Case-Based teaching discussion. Jiangsu higher education, 2000, (01):126. 